\title{
Healthcare Professional Experiences of Clinical Incident in Hong Kong: A Qualitative Study
}

\author{
Leung Andrew Luk' \\ Fung Kam Iris Lee $\mathbb{D}^{\prime}$ \\ Chi Shan Lam ${ }^{2}$ \\ Hing Yu So (D) ${ }^{3}$ \\ Yuk Yi Michelle Wong ${ }^{3}$ \\ Wai Sze Wacy Lui ${ }^{4}$
}

\begin{abstract}
'Nethersole Institute of Continuing Holistic Health Education (NICHE), Alice Ho Miu Ling Nethersole Charity Foundation, Hong Kong; ${ }^{2}$ Department of Anesthesiology \& Operating Services, AHNH \&NDH, Hong Kong; ${ }^{3}$ Quality \& Safety, New Territories East Cluster (Q\&S, NTEC), Hong Kong; ${ }^{4}$ Oasis Center for Personal Growth \& Crisis Intervention, Corporate Clinical Intervention, Corporate Clinical Psychological Services, Hospital Authority, Hong Kong
\end{abstract}

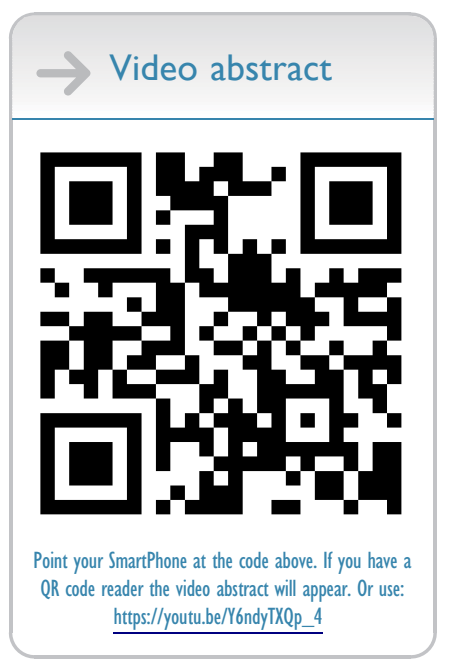

Correspondence: Leung Andrew Luk Email aluk@nethersole.org.hk

\author{
This article was published in the following Dove Press journal: \\ Risk Management and Healthcare Policy
}

\begin{abstract}
Background: Studies showed that adverse events within health care settings can lead to two victims. The first victim is the patient and family and the second victim is the involved healthcare professionals. However, there is a lack of research studying the experiences of healthcare professionals encountering clinical incidents in Hong Kong. This paper reports a qualitative study in exploring the healthcare professional experiences of clinical incident, their impacts and needs.
\end{abstract}

Methods: This study is the second part of the mixed research method with two studies conducted in a cluster of hospitals in Hong Kong. Study 1 was a quantitative questionnaire survey and Study 2 was a qualitative In-Depth Interview. In study 2, a semi-interview guide was used.

Results: Results showed that symptoms experienced after the clinical incident were mostly from psychological, physical, then social and lastly spiritual aspects which were consistent with those found in study 1 and other studies. Using content analysis for analyzing the impacts, four themes were identified. Concerning the impacts immediately from the clinical incident, two themes emerged were 1) facing emotion distress and 2) maintaining rationality. Regarding the impacts after the clinical incident, another two themes were 3) managing further emotional distress 4) restoring personal wellness. With regard to the needs after clinical incidents, three themes emerged were 1) self-recovery; 2) senior good mentoring and 3 ) positive organization climate with emphasis on enhancement of training and development of a positive practice culture.

Conclusion: Great impacts are found with healthcare professionals encountering clinical incidents from a holistic perspective. They need time for self-recovery with support from good supervisors, peers and a caring environment. Some recommendations based on the findings of the study are made.

Keywords: clinical incident, second victim, healthcare professionals, qualitative study

\section{Background}

Patient safety and high quality of care are fundamental to a patient-centered holistic care, which is also a demonstration of the excellence of a healthcare organization. Patient safety has long been a major concern of healthcare professionals working in hospital settings. However, studies show that there are complications of medical care or adverse events happen because of human or system errors during patients' hospitalization. In a landmark report by the Institute of Medicine in 1999, it was estimated that about 44,000 to 98,000 deaths occur each year in the United States as a result of medical errors. ${ }^{1}$ Based on these estimates, medical errors are ranked as the eighth leading cause of death in the United States. ${ }^{2}$ Health authorities of 
advanced countries such as the United States and the United Kingdom spell out the importance of learning from any errors, either caused by people or the healthcare system so as to minimize errors and create hospitals to be safer places for patients. ${ }^{3}$ With better understanding of errors and their contributing factors, it is hoped that the knowledge of healthcare professionals in the prevention of incidents can be increased. Furthermore, if errors are found in the hospital system, it can be redesigned to fill up the loopholes. Reporting system has been established by hospital management to gather information about medical errors so that mistakes can be learnt. In Hong Kong, the Advance Incident Reporting System (AIRS) has been set up by the Hospital Authority in 2004 to encourage hospital staff to report whenever incidents occur. Data are collected for analyzing obvious causes so that preventive measures can be taken to improve patient safety and quality of care. Besides, learning from errors, hospital staff are better trained to prevent and prepare for medical incidents.

However, improvements in hospital safety are still too slow in United States (US) as suggested by healthcare researchers. An overseas study in 2013 showed that an estimate of deaths, which may be due to preventable medical errors was up to 400,000 per year. ${ }^{4}$ That would make medical errors the third leading cause of death in America, which is behind the first, heart disease and the second, cancer. ${ }^{5}$ In Hong Kong, there is a lack of research on this area. Statistics from Hospital Authority in recent few years showed that there is a gradual reduction in the medical incidents. However, by September 2015, the number of reports submitted through Advance Incident Report System (AIRS) was over 117,000 since its establishment in $2004 .^{6}$

Beyond patient safety issue in hospital, health care industry is also one of the high-risk entities worldwide because of its high volume of users, complexity of procedures and involvement of many stakeholders. Overseas studies showed that healthcare professionals are under great stress and prone to burnout though they are providing incredibly meaningful and personally fulfilling job. Burnout is more commonly among physicians than other US workers. Physicians at frontline of care seem to be at the greatest risk. ${ }^{7}$ Nurses occupying a major workforce in hospital, one study showed that job-related stress affects nurses' lives and contributes to some forms of physical illness and may increase minor psychiatric morbidity. ${ }^{8}$ In Hong Kong, doctors and nurses are also under great risk when performing their duties in public hospitals where patient beds are usually fully occupied and workload is high, particularly if they are unprepared to face crisis at work. In a cross-sectional survey of 226 valid questionnaires from 1000 public doctors using the Maslach Burnout Inventory in Hong Kong, 31.4\% of the respondents suffered from high burnout. Young but moderately experienced doctors who need to work shifts appeared most vulnerable. ${ }^{9}$ A web-based cross-sectional survey on 850 nurses showed that nurses were more depressed, anxious and stressed than the local general population. Stress was significantly associated with younger age, clinical inexperience, past year disturbance with colleagues, low physical activity, no leisure and drinking alcohol. ${ }^{10}$ If doctors and nurses are under great stress and prone to burnout, it may lead to human errors.

Overseas studies showed that adverse events within health care settings can lead to two victims. The first victim is the patient and family and the second victim is the involved health care professional. ${ }^{11}$ The term second victim was introduced by $\mathrm{Wu}$ in 2000, and a specific definition was posed by Scott et al in 2009. ${ }^{12}$ The prevalence rates of second victims in a review study ${ }^{13}$ varied from $10.4 \%$ up to $43.3 \%$. A survey in the UK with 1463 doctors (83.3\%) reported having personally been involved in at least one near miss and/or adverse event at any point in their career. Of these, 1119 (76.5\%) believed that their experience had affected their personal or professional lives. ${ }^{11}$ Health care institutions and clinical leaders are called to take accountability and provide staff with formal and informal systems of support. ${ }^{14,15}$ However, there is no local research studying the impact of clinical incident on individual healthcare professionals. Clinical incident is defined by the research team of all errors involving near misses, preventable and negligent adverse events, and all adverse events including unanticipated non-preventable adverse events, but excluding anticipated non-preventable adverse events (ie side effect, complication or consequence of nature disease or treatment), and incidents that involve criminal act, deliberately unsafe act, substance abuse or deliberate patient harm or abuse.

There are two research questions in this study. They are: 1) what are the impacts on individual healthcare professional encountering a clinical incident? 2) what are their needs after the incident? The research may lead to a better understanding of the impact of clinical incident on health care providers in a holistic view. Their experiences may improve the support of future second victim and training to healthcare professionals in facing clinical incidents. 


\section{Methods}

A mixed research method was used in the main study with study 1 , a quantitative questionnaire survey and study 2, a qualitative In-Depth Interview. Regarding the study 2 reported here, a semi-interview guide was adopted and modified from Scott et al, 2009. ${ }^{12}$ The key questions asked were 1) think about a clinical incident from your past that impacted you both professionally and/or personally. Please share what you remember as specifically as possible from the moment that it was discovered that something was wrong. How did you respond to this event? How did it impact you? 2) What needs you experienced immediately after that event both personally and professionally. 3) What further impacts do you have afterwards? 4) What needs did you have afterwards? 5) What else would you like to share about your experience? The full semi-interview guide is attached in Appendix.

In study 1 , a random sample of healthcare professionals $(\mathrm{n}=2104)$ including doctors, nurses and allied health staff from the email list of a cluster of public hospitals $(n=5976)$ was generated. The random samples were invited via hospital email and invitation card to answer the online questionnaire survey from June to September 2017. Out of the final list of 2077, 387 questionnaires were returned with the rate of $18.6 \%$. Three hundred fifty-three (353) were valid for analysis. Participants who have randomly selected to answer the questionnaire in study 1 were also invited to participate in the second study after completing the questionnaire on a voluntary basis by leaving a contact email or telephone number. Voluntary participation and anonymity are ensured. The participants responded positively after the survey were contacted for an interview conducted by the first author in an interview room in their respective hospitals or office of NICHE. The study was further explained and a consent form was signed before the interview. The interview was audio-recorded and then transcribed by a research assistant. Content analysis was carried out to identify major themes in relation to the research questions. Analysis of the transcripts was conducted by two members of the research team and consensus was agreed on the related themes.

\section{Ethical Considerations}

A written informed consent to participate in the study including the publication of their responses was obtained from each participant. The present study was also conducted in accordance with the principles of the revised Declaration of Helsinki. Moreover, ethics approval of research protocol was obtained from Joint CUHK-NTEC Clinical Research Ethics Committee (CREC Reference number: 2016.465).

\section{Results \\ Background Information}

Fifteen healthcare professionals including 3 doctors, 10 nurses and 2 physiotherapists voluntarily contacted the researcher and were successfully interviewed. Most participants were female $(60 \%)$ with ages from 25 to 60 . Sixty percent of them got married. Working experiences ranged from less than 5 to more than 30 years. Sixty percentage of incidents happened less than 5 years ago. More than $70 \%$ of participants were the ones who encounter the incident. Nearly $90 \%$ of the incidents was with temporary or no harm to patients. Details can be seen in Table 1 .

\section{Symptoms Experienced After the Critical Incident}

When asked to review the list of symptoms that some staff have reported after the incidents, in terms of frequencies, most of them showed psychological, physical, then social and the lastly spiritual symptoms. Regarding the psychological symptoms, the top five were upset, shame, selfblame, anxious about future errors and fear of punishment. Relating to the physical symptoms, the top one is sleep disturbance followed by poor appetite and extreme fatigue. With regard to the social symptoms, both working relationship and professional reputation were affected, followed by decline in work performance and social withdrawal. As far as the spiritual symptoms were concerned, more were found in reduction in job satisfaction and only one responded with decreasing meaning at work. Details can be seen in Table 2 .

\section{Immediate Impacts from Clinical Incidents}

Totally four themes of impacts were emerged from the clinical incidents, two immediately and two afterwards. Regarding the immediate impacts, participants have to face their emotional distresses and maintain rationality. These two themes were generated by two categories, encountering intense negative emotions and seeking remedial measures at the same time. Immediately after the incidents, most of them suffered intense negative emotions including mainly shock, 
Table I Demographic Data $(\mathrm{N}=15)$ of Interview

\begin{tabular}{|c|c|c|c|}
\hline Sex & $\begin{array}{l}\text { Male } \\
\text { Female }\end{array}$ & $\begin{array}{l}6 \\
9\end{array}$ & $\begin{array}{l}40 \% \\
60 \%\end{array}$ \\
\hline Age & $\begin{array}{l}<25 \\
26-30 \\
3 I-35 \\
36-40 \\
4 I-45 \\
46-50 \\
>50\end{array}$ & $\begin{array}{l}0 \\
1 \\
2 \\
4 \\
2 \\
3 \\
3\end{array}$ & $\begin{array}{l}0 \% \\
7 \% \\
13 \% \\
27 \% \\
13 \% \\
20 \% \\
20 \%\end{array}$ \\
\hline Marital Status & $\begin{array}{l}\text { Married } \\
\text { Single }\end{array}$ & $\begin{array}{l}9 \\
6\end{array}$ & $\begin{array}{l}60 \% \\
40 \%\end{array}$ \\
\hline Profession & $\begin{array}{l}\text { Doctor } \\
\text { Nurse } \\
\text { Allied Health staff }\end{array}$ & $\begin{array}{l}3 \\
10 \\
2\end{array}$ & $\begin{array}{l}20 \% \\
67 \% \\
13 \%\end{array}$ \\
\hline Years of experience & $\begin{array}{l}<5 \\
5-10 \\
11-15 \\
16-20 \\
21-25 \\
26-30 \\
>30\end{array}$ & $\begin{array}{l}1 \\
1 \\
3 \\
6 \\
2 \\
1 \\
1\end{array}$ & $\begin{array}{l}7 \% \\
7 \% \\
20 \% \\
40 \% \\
13 \% \\
7 \% \\
7 \%\end{array}$ \\
\hline Event happened year ago & $\begin{array}{l}1 \\
2 \\
3 \\
4 \\
5 \\
6 \\
7 \\
>7\end{array}$ & $\begin{array}{l}4 \\
2 \\
1 \\
2 \\
2 \\
1 \\
1 \\
2\end{array}$ & $\begin{array}{l}27 \% \\
13 \% \\
7 \% \\
13 \% \\
13 \% \\
7 \% \\
7 \% \\
13 \%\end{array}$ \\
\hline Role in event & $\begin{array}{l}\text { First encounter } \\
\text { Second/supervisor } \\
\text { Both }\end{array}$ & $\begin{array}{l}11 \\
4 \\
0\end{array}$ & $\begin{array}{l}73 \% \\
27 \% \\
0 \%\end{array}$ \\
\hline Patient outcomes & $\begin{array}{l}\text { No harm } \\
\text { Temporary harm } \\
\text { Permanent harm } \\
\text { Death }\end{array}$ & $\begin{array}{l}6 \\
7 \\
0 \\
2\end{array}$ & $\begin{array}{l}40 \% \\
47 \% \\
0 \% \\
13 \%\end{array}$ \\
\hline
\end{tabular}

anxiety, shame and guilt. However, some participants focused more on solving the problems and controlling their emotion with rationality. Details can be seen in Table 3 and some of the descriptions are as follows.

\section{Facing Emotional Distress}

\section{Encountering Intense Negative Emotions}

Shock, Guilt

After the incident, my colleague and I suddenly awoke up, what we had done, why we were doing these things?
Table 2 Frequencies of Symptoms Experienced After the Medical Incident

\begin{tabular}{|c|c|}
\hline Physical & $\begin{array}{l}\text { - Sleep disturbance } \times 9 \\
\text { - Poor appetite } \times 4 \\
\text { - Extreme fatigue } \times 3\end{array}$ \\
\hline Psychological & $\begin{array}{l}\text { - Upset } \times 10 \\
\text { - Shame } \times 8 \\
\text { - Self-blame } \times 8 \\
\text { - Anxious about future errors } \times 7 \\
\text { - Fear of punishment } \times 7 \\
\text { - Anger } \times 6 \\
\text { - Guilt } \times 6 \\
\text { - Feeling of incompetence } \times 5 \\
\text { - Irritation } \times 5 \\
\text { - Self-doubt } \times 5 \\
\text { - Loss of self-confidence } \times 4 \\
\text { - Depression } \times 3 \\
\text { - Others }- \text { helplessness } \times 2 \\
\text { - Others }- \text { ambivalence } \times 1\end{array}$ \\
\hline Social & $\begin{array}{l}\text { - Affect working relationship } \times 4 \\
\text { - Affect professional reputation } \times 4 \\
\text { - Decline in work performance } \times 3 \\
\text { - Social withdrawal } \times 2 \\
\text { - Others }\end{array}$ \\
\hline Spiritual & $\begin{array}{l}\text { - Reduction in job satisfaction } \times 4 \\
\text { - Decreasing meaning at work } \times 1\end{array}$ \\
\hline
\end{tabular}

Totally awoke. When we evaluated, why this would happen? As we were not very calm, we could say that we were too busy, being too busy, making us want to finish the task as soon as possible, we just did what we had seen,

Table 3 Codes, Categories, and Themes of Impacts Immediately from Critical Incidents

\begin{tabular}{|l|l|l|}
\hline Themes & Categories & Codes \\
\hline Facing emotional & $\begin{array}{l}\text { Encountering intense } \\
\text { negative emotions }\end{array}$ & $\begin{array}{l}\text { Shock } \times 4 \\
\text { Surprise } \times 2 \\
\text { Anxiety } \times 4 \\
\text { Shame } \times 3 \\
\text { Guilt } \times 3 \\
\text { Fear } \times 2\end{array}$ \\
& & $\begin{array}{l}\text { Solve problem } \\
\times 3 \\
\text { Maintaining } \\
\text { rationality }\end{array}$ \\
& Seeking remedial measures \\
& & $\begin{array}{l}\text { Rationalization } \\
\times 1 \\
\text { Control } \\
\text { emotion } \times 1 \\
\end{array}$ \\
& & $\begin{array}{l}\text { Positive self- } \\
\text { talk } \times 1\end{array}$ \\
\hline
\end{tabular}


could you get it? Did what we had seen, when we realized something went wrong, we were so shocked, we did not say anything, as we are very senior, we are very shocked, did not know what to do. The day after, I felt very bad, the worst moment, I could not be able to accept it, why I made such a mistake? I could not accept it, as you are not a new graduate. You also thought it was a serious incident, although the consequence was not serious to the patient, the transient high blood pressure would be lowered, you know the patient, this harm was not really harmful, but that category of medicine is a high risk drug, we all had the feeling of unforgiving to ourselves, we took this feeling to continue our work. (Case 15, a senior registered nurse)

In the ward, that case was stable, so the doctor gave 1-2 weeks home leave to the patient, as far as I knew the case, during the intervention, there were no hints of suicidal risk, so when the colleague heard the news, he was very shocked. The patient jumped on Sunday before returning to the ward after home leave. When the patient was no show, we traced the case, we came to know what had happened. It was so shock for that colleague, he worked with the patient for such a long period of time, he thought "was there anything he had missed in his caring with the patient?" I thought he might have a little bit of guilty feeling too. (Case 13, an Advanced Practice Nurse)

\section{Anxiety}

She knew it at 8 am, no one called me till $2 \mathrm{pm}$. The ward manager was on long leave. Do you know what I have to do next? Asked the colleague to report to AIRS, then called the General Manager (N), the public relations, Patient \& Safety Officer, Chief Of Service (COS) of the unit. Asked the COS to tell the Hospital Chief Executive, do you understand? You made 5 phone calls, you also had to call the colleague on night shift duty, who was the one on Am shift, responsible to report the incident. The GM(N) happened in the hospital and came to ask if the in-charge had reported the incident to AIRS. Not yet, then you went back to hospital to report it, can you get it? What did I do that day? I went to two patient voluntary groups, the diabetes group, they had outing. Sometimes, you could not think the things too simple, you needed to consider the consequences, we did not know how much the patient would suffer. Fortunately, the thoracic surgery of our sister hospital helped to take it out. (Case 4, a Department Operation Manager)

\section{Shame}

In fact, I felt very shameful because the relative brought out the wrong drug and asked me. At that moment, I thought: Oh, my God, I totally lose my face. I was seemed to be a thief and was caught red handed by the relative or a person who had done something wrong and was blamed. I really wanted to dig a hole in the ground and hide from the relative. (Case 9, a ward manager)

\section{Maintaining Rationality Seeking Remedial Measures Solving Problem}

Quickly solve the problem, - and see there is no other persons get hurt. That is, you don't think whether the incident may be reported in the newspaper, or you will be answerable to the incident. In fact, I really don't have anything in mind but solving the problem. (Case 2, a doctor)

When I faced my colleague who committed an incident, I only wanted to know what he/she had done, what else did I need to know to make remedy, I needed to fix it right away, so I did not think of my own need, am I too rational? (Case 4, a Department Operation Manager)

\section{Control Emotion}

You had to calm down yourself first, told yourself not to let the emotion fluctuate too much, because you got to work the next day, you had daytime duty. If your emotion are too fluctuated, you would not have a clear mind, and good performance, and you would have unnecessary suspicions. When the manager or in-charge walked over, you would guess he/she was looking for you. Then, told yourself not to think too much, finished your job as soon as possible as there were so many things to be done. And maybe being occupied when you were at work, after work, you would think over it again, review it again, re-run it in your mind. Pondering what things could be done better, not to make the same mistake next time, re-experience the feeling, that is, how to make yourself become less helpless. (Case 6, a senior registered nurse)

\section{Positive Self Talk}

I told yourself, no one could help you. Even you told others for a number of times, it was no use. Wrong was wrong, they would ask you to settle the incident, the most important thing is to settle the event as soon as possible. Try to know 
what will be your next target, for example, find the patient, if the patient was fine, then after the emotion was faded out and you would be fine. (Case 6, a senior registered nurse)

\section{Impacts After Clinical Incidents}

Relating to impacts afterwards, they have to manage further emotional distresses and restore personal wellbeing. These two themes were generated by three categories, encountering additional negative emotions, facing sleep disturbances and receiving extra support. Having provided remedial measures, most participants have encountered additional negative emotions such as not being understood of committing the incident, being blamed and felt being treated unfairly. Some of them suffered sleep disturbances. However, many of them received extra support from supervisors and colleagues which help them overcome the crisis. Details can be seen in Table 4 and some of the descriptions are as follows.

\section{Managing Further Emotional Distress Encountering Additional Negative Emotions Not Being Understood}

Only after I had been blamed, a copy of guideline was given for my reference. I thought I was the one who found nowhere to make a complaint for my injustice. It seemed that everyone would tell you there were some points to follow, but many were after the incident, could more things be done in advance, so took the

Table 4 Codes, Categories, and Themes of Impacts After Medical Incidents

\begin{tabular}{|l|l|l|}
\hline Themes & Categories & Codes \\
\hline $\begin{array}{l}\text { Managing further } \\
\text { emotional distress }\end{array}$ & $\begin{array}{l}\text { Encountering additional } \\
\text { negative emotions }\end{array}$ & $\begin{array}{l}\text { Not being } \\
\text { understood } \times 5 \\
\text { Being blamed } \times 4 \\
\text { Felt treated } \\
\text { unfair } \times 3\end{array}$ \\
\cline { 2 - 3 } & Facing sleep disturbances & $\begin{array}{l}\text { Insomnia } \times 1 \\
\text { Nightmare } \times 1\end{array}$ \\
\hline Restoring personal & Receiving extra support & $\begin{array}{l}\text { Support from } \\
\text { supervisors } \times 4 \\
\text { Support from } \\
\text { colleagues } \times 3 \\
\text { Asking for help } \\
\times \text { I } \\
\text { Self reflection } \\
\text { x I }\end{array}$ \\
\hline
\end{tabular}

initiative to help those with less experience. (Case 6, a senior registered nurse)

\section{Being Blamed, Criticized}

Some of your colleagues, the nurses, if you don't mind, they messed up the things when handing over duty. 'The patient complained pain, it was like that after the physio therapy.' Sometimes they put the matter onto you as they didn't grasp the whole picture. As to some patients, there were some known risks. We have done what we should do. The impacts made you feel very uncomfortable. Although not to the point of being blamed, it already made you feel very uncomfortable. You were complained by the patient of hurting her, I could do nothing. (Case 14, a physiotherapist)

When I went back home, I was really angry. I was thinking what mistakes had I made, I thought it was unfair to me, I wondered why it would happen? Was that his practice? Then after a period of time for understanding, I realized the reason behind. (Case 5, a doctor)

\section{Facing Sleep Disturbances \\ Nightmare}

That incident made me very unhappy for a period of time. During that period, you spontaneously had nightmares. I thought my emotions had been affected, and of course, it faded out with time passed. (Case 14, a physiotherapist)

\section{Restoring Personal Well-Being Receiving Extra Support \\ Support from Supervisors}

I thought the shift in-charge was very good. At that time, many people liked to ask what had happened. But she did not ask anything, we knew that we had to report the incident to her, however, I had no mood to do anything in that shift but unwillingly continued to complete the task at hand till the end of that shift and that was all. I really appreciated her of neither pressing us to do anything, nor chasing us for incident reporting. On the other hand, I told her: ' I am sorry, I am very busy now, I will report the whole incident to you when I am ready.' She replied: 'it doesn't matter, take your time.' Regarding the incident, I think she is the most supportive senior. (Case 15, a senior registered nurse) 


\section{Support from Colleagues}

Honestly, facing incident, people like to find someone for ventilation. Who is the one just nearby? Of course, nurses. You may query whether it is effective, unless it is a very serious event, which is very critical and no one around can give you a hand. So there is a need to look for professional help. Otherwise, if not to that level, then colleagues would be okay. (Case 3, an Advanced Practice Nurse)

\section{Asking for Help}

It depends on the seriousness of the incident, sometimes, I would go to my peer. It helps if we are on the same duty shift, such as for handling complaints. But for some serious incidents, I would seek help from my senior. At that moment, I would go to my ward manager. Those incident like accident, might not be very serious, but still I would seek their help as there will be many follow up issues to handle. If the incident could be settled at the scene, then I would handle it with my peer. (Case 9, a ward manager)

\section{Self-Reflection}

When I went back home, I reflected by myself, how could such thing happen. It would be terrible if people do not know how to reflect. We need to have reflection, checking where the mistake comes from, the self or the others, etc. (Case 7, an Advanced Practice Nurse)

\section{Needs After Clinical Incidents}

Three themes generating from the needs after clinical incidents included self-recovery, senior good mentoring and positive organizational climate. Regarding the self-recovery, many participants expected taking a break and one even thought of changing of workplace in order to allowing time for selfrecuperation. At the same time, seeking social support including sharing with friends, colleagues and spouse was common. Relating to the senior good mentoring, many participants expected senior emotional support by showing understanding, care and concern. While some also expected senior practical support by giving time for ventilation and offering guidance in clinical areas. With regard to the last theme of positive organization climate, it involves enhancement of training by providing more knowledge and skill and develop positive attitude. Further, some participants mentioned the development of positive practice culture with no blame from colleagues and improvement in handover sharing. Details can be seen in Table 5 and some of the descriptions are as follows.

\section{Self Recovery \\ Self Recuperation}

Take a Break

"If the emotion had been affected, not very stable, then should take a few days off, to calm yourself down." (Case 12 , a registered nurse)

\section{Seeking Social Support}

Share with Friends

"I can only share with those at my level." (Case 4, a Department Operation Manager)

\section{Share with Spouse}

When I go back home, I talk to my wife, does it cause any impact? It has some, that is bringing your work back home, but I have to find someone to air out, anyway it

Table 5 Codes, Categories, and Themes of the Needs After Critical Incidents

\begin{tabular}{|c|c|c|}
\hline Themes & Categories & Codes \\
\hline \multirow[t]{2}{*}{ Self recovery } & Self recuperation & $\begin{array}{l}\text { Take a break } \times 4 \\
\text { Change working place } \\
\text { × I }\end{array}$ \\
\hline & Seeking social support & $\begin{array}{l}\text { Share with friends or } \\
\text { colleagues } \times 3 \\
\text { Share with spouse } \times 1 \\
\text { Support from } \\
\text { Fellowship } \times 1\end{array}$ \\
\hline \multirow[t]{2}{*}{$\begin{array}{l}\text { Senior good } \\
\text { mentoring }\end{array}$} & $\begin{array}{l}\text { Senior emotional } \\
\text { support }\end{array}$ & $\begin{array}{l}\text { Senior show } \\
\text { understanding } \times 3 \\
\text { Care and concern } \times 3\end{array}$ \\
\hline & Senior practical help & $\begin{array}{l}\text { Guidance } \times 3 \\
\text { Chance for ventilation } \\
\times 2\end{array}$ \\
\hline \multirow[t]{2}{*}{$\begin{array}{l}\text { Positive } \\
\text { organizational } \\
\text { climate }\end{array}$} & $\begin{array}{l}\text { Enhancement of } \\
\text { training }\end{array}$ & $\begin{array}{l}\text { Increase knowledge } \\
\text { and skill } \times 3 \\
\text { Learning by modelling } \\
\times 1 \\
\text { Appropriate person } \\
\text { for support } \times \text { I } \\
\text { Develop positive } \\
\text { attitude } \times 1\end{array}$ \\
\hline & $\begin{array}{l}\text { Development of } \\
\text { positive practice } \\
\text { culture }\end{array}$ & $\begin{array}{l}\text { Not to gossip within } \\
\text { groups } \times 2 \\
\text { Handover sharing } \times 2 \\
\text { Develop no blame and } \\
\text { caring culture } \times 1\end{array}$ \\
\hline
\end{tabular}


would not last too long, but what last longer is the relationship with my colleague. (Case 5, a doctor)

\section{Senior Good Mentoring Senior Emotional Support \\ Showing Understanding}

Would go to the senior, to the one who can be trusted. That trusted senior is not only knowledgeable but also understandable, that is, understanding people would make mistake. Some seniors do not like that, they are smart, but cannot understand. When they see you, they criticize you right away, ask how you can make such a mistake, etc. If you meet someone who can understand, should have knowledge as well, otherwise, if have understanding but no knowledge, it is still no use. (Case 7, an Advanced Practice Nurse)

\section{Senior Practical Help \\ Guidance}

At that time, since I was so junior, I did not came across with 'missing' all the time. Hope someone with experience could give me a hand and guide me. At least say something for you, not only myself stand in the front for confrontation. (Case 6, a senior registered nurse)

We would handle it together, then really handle it together practically or delegate to some appropriate colleagues with the one who has involved in the incident to handle it properly. Everyone takes their responsibilities. Sometimes we would blame others, we may pass the ball to others. Don't let our colleagues have that kind of feeling. We share the responsibility and we face the situation together. After settling down the incident, feedback to that colleague if something is good, emphasize it back to him/her that something you have done very well, although not very mature, or not very experienced. If there are something good, emphasize the good points. After every incident, colleagues would always look at their negative side, maybe they have done 10 things, 9 are good, 1 is bad, but they only look at the bad one. We have to point out the 9 good things they have done. I think this is the best way for the feeling of our colleagues. (Case 13, an Advanced Practice Nurse)

\section{Chance for Ventilation}

They need to express themselves, don't always ask why making the mistake, why it happens. Haven't you checked clearly while distributing the medicine, such kind of words should be minimized. On the contrary, we should explore how do they feel at this moment. (Case 11, a Department Operation Manager)

\section{Positive Organizational Climate Enhancement of Training Increase Knowledge and Skill}

We have to prepare ourselves to face incidents, which is better than you don't know what to do in the incident. As senior as I am, I have this kind of thinking. As for the juniors, they may not have this kind of thinking and they need help. They need some personal support. (Case 11, a Department Operation Manager)

\section{Learnt by Modeling}

Some seniors, in a short distance, for instance, when handover duty, perform a role play or when the in-charge sees that you cannot manage the incident, he/she takes initiative to help you to manage. In fact, it is already a demonstration, then we can learn. (Case 6, a senior registered nurse)

\section{Develop Positive Attitude}

I think the incident has already happened, we cannot change anything. What we can do is helping the colleague face it. As you say, incident is unavoidable, it happens in this way today and that way on the other day. We need to develop ourselves, with a positive attitude, help the people around know how to face it. If you are negative, it would spread drastically, but for positive energy, you need to make a great effort. (Case 11, a Department Operation Manager)

\section{Development of Positive Practice Culture No Gossip Within Groups}

I think if something happens among our colleagues, we really should not gossip. Gossip is very bad. Some people are really bad when they read the newspaper and take the information as if they are their own experiences, then talk it loudly at pantry. If the person involved is there and hears what they say, while the source of those harmful information being reported is unknown, and staff involved still have to listen to it, and even with added inaccurate elaboration, it really hurts that person. Even not heard by that person, you know the world is so small, someone would tell the involved staff later. (Case 7, an Advanced Practice Nurse) 


\section{Handover Sharing}

During these few years, the manager at the time of handover would sometimes, hide the name of the ward, tell the story, make a reflection with us, point out the risk factors and let everyone learn a lesson. (Case 6, a senior registered nurse)

\section{Develop No Blame and Caring Culture}

It is good to explore the problems of the system and will not blame the staff at the beginning. I think the culture makes you feel that people won't blame the staff if there are any incidents. They would explore any room for improvement of the system. That staff would have good feeling. Of course, some could not shift their responsibilities due to negligence such as administration of drugs. You should be responsible if you have not done all the checking procedures, sometimes, it happens. But the culture makes you feel that you are not blaming the staff. I am impressed by the quote of the HCE that 'no bad apple', that is, everyone goes to find out the reason from the incident. (Case 14, a physiotherapist)

\section{Discussion}

\section{Symptoms Experienced After the Critical Incidents}

Psychological symptoms such as upset, shame, anxious about future errors, fear of punishment comes most, then physical symptom with sleep disturbance and social and spiritual symptom come less. They are consistent with the symptoms identified in the quantitative study 1 and with other overseas studies. ${ }^{11,12,16,17}$

\section{Immediate Impacts}

This study found that beyond the intense negative emotions such as anxiety, shame, guilt and fear which are commonly identified in other studies, ${ }^{17,18}$ a state of shock and surprise were revealed from some participants. Facing an error at the first movement is difficult especially for those who are devoted to their profession and never commit an error before. It is important for the supervisor to understand the psychological stresses at the very moment when the error is found. Providing emotional support to the staff when the incident has happened and help manage the patient at the same time are both important in any critical incident. Furthermore, the staff involved have to control their negative emotion and try to take remedial measures to their patients at the same time. Therefore, it is not only necessary for the healthcare professional to be well trained in the prevention and management of critical incidents, but also personal growth training in resilience in the healthcare setting where human life is concerned.

\section{Impacts Afterwards}

This study showed that participants still faced further emotional distresses such as not being understood, being blamed for the error and some may perceive treated unfairly. In the management of the post-crisis, understanding showed by management, supervisors and colleagues are important. It is always emphasized by overseas studies that when promoting a patient safety culture, a no blame culture should be developed at the same time for the wellbeing of the staff involved. ${ }^{19,20}$ Regarding critical incidents, staff involved will suffer from different degree of impact with emotional distress. For those involved with serious incident, the process of investigation takes time and impacts will last for longer. The ways of restoring personal wellness by self-reflection and supports from others identified in this study is also found with the local studies of the managing job difficulties of healthcare professionals by means of self -adjustment and help from others $^{21,22}$ and consistent with other overseas studies. ${ }^{19,20}$

\section{Needs After Clinical Incidents}

This study found that needs required starting from oneself, others and then the organization. The findings showed that a number of staff would like to take a break immediately after an incident even though investigation has to be carried out and documentation has to be filed since it may be too stressful for the staff involved to manage the personal impacts. The management should consider whether the staff is under too much stress, who may need to be released for a few days off for calming down oneself. Support from supervisors in terms of showing understanding and providing practical help is expected as shown by some of the participants. Frontline supervisors should be better equipped to lead their subordinates. Good modelling from senior staff and making effective communication about the lessons learnt from recent critical incidents during handover time seem to be better ways of training in the ward level. Regarding the support from the organization, enhancement of training and development of a positive practice culture are expected. More effort should be put in the training for the frontline managers and staff so that 
a supportive and trustful culture can be developed for the benefits of both patients and staff. Some training and emotional support programs have also been found successful in the prevention and support for staff in critical incidents. ${ }^{19,23}$

\section{Limitations}

One of the limitations of this study is small sample size, however, all participants were eager to share their experiences and aimed at their voices being heard, rich sharing help reach data saturation. Another is some incidents are sensitive which may lead to the leak of participant's privacy. Description of some incidents has to be erased from the verbatim but the rest remains at illustrating their impacts and needs.

\section{Recommendations}

Based on the findings of this study, some recommendations are as follows:

\section{Individual}

Since healthcare professionals are in a high-risk position in hospital to manage with patient life and emotional labor, they not only need to be professionally prepared, but also need to build up strong characters to face life adversity and crisis. A national survey of Intensive Care Unit nurses showed that the presence of resilience is associated with a healthier psychological profile and a lower prevalence of post-traumatic stress disorder and burnout syndrome. ${ }^{24}$ Achievement in resilience either by personal enhancement or in-service training is required.

\section{Department}

Leadership is an important component to build a good team in the department. All supervisors should be well equipped with leadership skill so that mutual support and trust can be developed in the department to facilitate smooth running of the service. During time of crisis, peer support can be provided more easily with a trustful relationship within the team. Leadership training to frontline and middle managers should be enhanced as clinical incident prevention and intervention management since studies have persistently showed that quality healthcare is dependent on effective interdisciplinary teamwork and good leadership. ${ }^{25,26}$ Furthermore, a better communication using handover time and ward meeting for knowledge and skills learnt from critical incidents should be enhanced.

\section{Organization}

As there is appeal from families and patients harmed by medical errors for the abandonment of the term of "second victim", ${ }^{27}$ it is worth for the administrator of the Hospital Authority to provide a balance between taking care of staff at the same time with the patients and families in the critical incidents. Over-emphasis on taking care of the staff involved may give a false impression to the public that the organization would like to protect their staff and avoid taking accountability in the incident. On the other hand, more effort should be provided to develop a no blame and caring culture so that support within the team can be enhanced no matter there is clinical incident or not. Study showed that in a compassionate healthcare setting, patients and staff would feel listened to, supported, and cared for. ${ }^{28}$ Working in a supportive and caring environment has long been found to create more meaning in one's life which is also a motivator for work. ${ }^{29,30}$

\section{Conclusion}

There is an increasing concern of the holistic health of healthcare professionals who have encountered clinical incidents in hospitals. This study showed that immediately from the clinical incident, they experience intense emotional distress while maintaining rationality for remedial measures. Regarding the impacts after the clinical incident, they still have to face further emotional distress and try to restore personal wellness. With regard to the needs after clinical incidents, they need time for self-recovery, senior good mentoring and positive organization support with emphasis on enhancement of training and development of a positive practice culture. Finally, some recommendations were made.

\section{Acknowledgment}

The research team would like to express gratitude to OASIS for contingency psychological support during interview process for any sensitive issue and emotional arousal that needs special attention.

Special thanks are also extended to the Alice Ho Miu Ling Nethersole Charity Foundation for the funding of the whole project.

We would also like to thank the local academic advisor, Professor Shui-Man Simon Kwan of The Chinese University of Hong Kong, and the international academic advisorProfessor Harold G. Koenig of the Duke University. 


\section{Disclosure}

Dr Chi Shan Lam reports grant from Alice Ho Miu Ling Nethesole Charity Foundation, during the conduct of the study. The authors report no other conflicts of interest in this work.

\section{References}

1. Brennan TA, Leape LL, Laird NM, et al. Incidence of adverse events and negligence in hospitalized patients: results of the Harvard Medical Practice Study I. N Eng J Med. 1991;324(6):370-376. doi:10.1056/NEJM199102073240604

2. Kohn LT, Corrigan JM, Donaldson MS. To Err is Human: Building a Safer Health Care System. National Academy Press; 1999.

3. Department of Health. An Organisation with a Memory: Report of an Expert Group on Learning from Adverse Events in the NHS. HMSO; 2000.

4. James JT. A new, evidence-based estimate of patient harms associated with hospital care. $J$ Patient Saf. 2013;9(3):122-128. doi:10.1097/PTS.0b013e3182948a69

5. Center for Disease Control and Prevention. Deaths and mortality; 2015. Available from http://www.cdc.gov/nchs/fastats/lcod.htm.

6. Hospital Authority. Annual report on sentinel and serous untoward events (Oct 2014 to Sept 2015). Hong Kong: Patient Safety and Risk Management Department, Hospital Authority; 2016.

7. Shanafelt TD, Boone S, Tan L, et al. Burnout and satisfaction with work-life balance among US physicians relative to the general US population. Arch Int Med. 2012;172(18):1377-1385. doi:10.1001/ archinternmed.2012.3199

8. Golvbasi Z, Kelleci M, Dogan S. Relationships between coping strategies, individual characteristics and job satisfaction in a sample of hospital nurses: cross-sectional questionnaire survey. Int $J$ Nurs Stud. 2008;45(12):1800-1806. doi:10.1016/j.ijnurstu.2008.06.009

9. Siu CFY, Yuen SK, Cheung AC. Burnout among public doctors in Hong Kong: cross-sectional survey. Hong Kong Med J. 2012;18 (3):186-192.

10. Cheung T, Yip PSF. Depression, anxiety and symptoms of stress among Hong Kong nurses: a cross-sectional study. Int J Environ Res Public Health. 2015;12(9):11072-11100. doi:10.3390/ijerph120911072

11. Harrison R, Lawton R, Stewart K. Doctors' experiences of adverse events in secondary care: the professional and personal impact. Clin Med. 2014;14(6):585-590. doi:10.7861/clinmedicine.14-6-585

12. Scott SD, Hirschinger LE, Cox KR, McCoig M, Brandt J, Hall LW. The natural history of recovery for the healthcare provider "second victim" after adverse patient events. Qual Saf Health Care. 2009;18 (5):325-330. doi:10.1136/qshc.2009.032870

13. Seys D, Wu AW, Gerven EV, et al. Health care professionals as second victims after adverse events: a systematic review. Eval Health Prof. 2013;36(2):135-162. doi:10.1177/0163278712458918

14. Schwappach DLB, Boluarte TA. The emotional impact of medical error involvement on physicians: a call for leadership and organisational accountability 2008. Swiss Med Wkly. 2008;14:1-7.
15. White AA, Waterman AD, McCotter P, Boyle DJ, Gallagher TH. Supporting health care workers after medical error: considerations for health care leaders. J Clin Outcomes Manag. 2008;15(5):240-247.

16. Waterman AD, Garbutt J, Hazel E, et al. The emotional impact of medical errors on practicing physicians in the United States and Canada. Jt Comm J Qual Patient Saf. 2007;33(8):467-476. doi:10.1016/S1553-7250(07)33050-X

17. Zhang X, Li QY, Guo YH, Lee SY. From organizational support to second victim-related distress: role of patient safety culture. J Nurs Manag. 2019;27(8):1818-1825. doi:10.1111/jonm.12881

18. Nydoo P, Pillay BJ, Naicker T, Moodley J. The second victim phenomenon in health care: a literature review. Scand J Public Health. 2019;47(1):1-9. doi:10.1177/1403494818774965

19. Hirschinger LE, Scott SD, Hahn-Cover K. Clinician support: five years of lessons learned. Patient Saf Qual Health Care. 2015;12 (2):26-31.

20. McDonald TB, Helmchen LA, Smith KM, et al. Responding to patient safety incidents: the seven pillars. Patient Saf Qual Health Care. 2012;19(e11).

21. Luk AL, Yau AF. Experiences of public doctors on managing work difficulties and maintaining professional enthusiasm in acute general hospitals: a qualitative study. Front Public Health. 2018;19. doi:10.3389/fpubh.2018.00019.

22. Luk L, Tung WC. An exploration of the difficulties in practicing holistic care by nurses in clinical setting and their overcoming strategies. Nurs Sci. 2018;7(2):61-70. doi:10.12677/ns.2018.72012.

23. White AA, Brock DM, McCotter PI, et al. Risk managers' descriptions of programs to support second victims after adverse events. J Healthc Risk Manag. 2015;34(4):30-40. doi:10.1002/jhrm.21169

24. Mealer M, Jones J, Newmana J, McFann KK, Rothbaum B, Moss M. The presence of resilience is associated with a healthier psychological profile in intensive care unit (ICU) nurses: results of a national survey. Int $J$ Nurs Stud. 2012;49(3):292-299. doi:10.1016/j. ijnurstu.2011.09.015

25. McAlearney AS. Using leadership development programs to improve quality and efficiency in healthcare. $J$ Healthc Manag. 2008;53 (5):319-331.

26. Ackerman M, Malloch K, Wade D, et al. The master in healthcare innovation: a new paradigm in healthcare leadership development. Nurse Lead. 2019;17(1):49-53. doi:10.1016/j.mnl.2018.09.010

27. Clarkson MD, Haskell H, Hemmelgarn C, Skolnik PJ. Abandon the term "second victim". BMJ. 2019;364:11233. doi:10.1136/bmj.11233

28. de Zulueta PC. Developing compassionate leadership in health care: an integrative review. J Healthc Leadersh. 2015;8:1-10. doi:10.2147/ JHL.S93724

29. Ashmos DP, Duchon D. Spirituality at work: a conceptualization and measure. J Manag Inq. 2000;9(2):134-145. doi:10.1177/ 105649260092008

30. Duchon D, Ashmos DP. Nurturing the spirit at work: impact on work unit performance. Leadersh Q. 2005;16(5):807-833. doi:10.1016/j. leaqua.2005.07.008
Risk Management and Healthcare Policy is an international, peerreviewed, open access journal focusing on all aspects of public health, policy, and preventative measures to promote good health and improve morbidity and mortality in the population. The journa welcomes submitted papers covering original research, basic science, clinical \& epidemiological studies, reviews and evaluations, guidelines, expert opinion and commentary, case reports and extended reports. The manuscript management system is completely online and includes a very quick and fair peer-review system, which is all easy to use. Visit http://www.dovepress.com/testimonials.php to read real quotes from published authors. 